\title{
Established and outsider nationals: Immigrant-native relations and the everyday politics of national belonging
}

\section{Abstract}

Ideologies of national belonging and related perceptions of the need to secure the boundedness of the national entity prevail in the design of migration policy in the western world. The same ideologies also account for discourses and policies questioning the belongingness of immigrants after settlement. Prolonged stays by migrants, especially those of low class standing, are seen as a threat to the social cohesion and cultural homogeneity of the nation, and the acceptance of newcomers is provisional upon their compliance with a set of norms and behaviors, dispelling impressions of their perceived dangerous character. Such ideologies are not only macro-structural forces produced through the workings of state institutions but, equally, are enacted and contested through the practices of 'ordinary people' in different fields of everyday social life. Elias and Scotson's (1994) established-outsiders model provides an appropriate theory with which to understand these everyday dynamics allowing for a relational perspective that situates processes of domination and resistance at the heart of the inquiry.

Expanding on this model and the literature on 'whiteness' and everyday nationhood, this paper puts forward an intersectional theoretical framework that views immigrant-native relations as unequal configurations unfolding through a symbolic struggle over defining the nation and who belongs to it. In so doing, it brings in the dimension of power in the study of immigrant integration.

\section{Keywords}

Established and outsiders, politics of national belonging, immigrant-native relations, immigrant integration, intersectionality, whiteness, everyday nationhood 


\section{Introduction}

International immigrants, by their mere act of crossing national borders, challenge ideologies which make claims for the territorial and ethnic boundedness of the national entity. They constitute 'problematic exceptions' to the nationalist image of normal life which prescribes that people should stay in the places where they belong, that is, in 'their' nation-states (Wimmer and Glick Schiller, 2002: 131). Such ideologies and the perceived need to secure the boundedness of the national entity prevail in the design of migration policy in the western world and in Europe in particular, in which inflows of disadvantaged persons are treated as aggressive invasions and penalization of entry is seen as the solution to the 'problem'. The same ideologies also account for discourses and policies questioning the belongingness of immigrants after settlement. Prolonged stays by migrants, especially those of low class standing, are seen as a threat to the social cohesion and cultural homogeneity of the nation, and the acceptance of newcomers is provisional upon their compliance with a set of norms and behaviors dispelling impressions of their perceived dangerous character (Pratsinakis et al., 2015; Sayad, 2004).

The role of ideologies of national belonging in the increasingly restrictive and criminalizing migration policies, and the dramatic consequences of these policies for people attempting to reach western destinations, is acknowledged and problematized in 
the migration literature (Coutin, 2010; Fassin, 2011; Malkki, 1995; Turner, 2007). However, migration scholars who have focussed their research on the processes that pertain to the settlement of immigrants have paid less attention to the hegemonic role of ideologies of national belonging in shaping processes of inclusion/exclusion. Despite the recent academic attention on European states' increasing demands upon immigrants to prove their belonging and loyalty (Kofman, 2005; Van Houdt et al., 2011; Yuval Davis, 2011) - as expressed in residence permit and citizenship acquisition requirements - and the rapidly growing literature on the (re-)production of ideologies of national belonging in everyday life (Brubaker et al., 2006; Edensor, 2002; Leddy-Owen, 2014; Skey, 2011; Vassenden, 2010), limited research has been done by migration scholars on how those ideologies are experienced, negotiated and contested by immigrants and natives in their day-to-day interactions and, most importantly, on how they influence the figuration in which their mutual relationship is cast.

This paper argues that Elias and Scotson's (1994) established-outsiders model provides an appropriate analytical framework with which to address this dynamic. This model, developed from the study of a community, Winston Parva, illustrates how power differences between groups permit the creation of polarized status distinctions between the group charisma claimed by the 'established', and the complementary communal disgrace that they attribute to those they construct as 'outsiders'. Considering the figuration studied in Winston Parva as particularly illuminating in uncovering the basic 
mechanism of established-outsider relationships, Elias (1994: xvii) ${ }^{\mathrm{i}}$ called for the application of the model in larger and more complex figurations. Here I extend the established-outsider model to account for figurations resulting from international migration, rather than from internal migration as was the model originally developed here. Based on this model and drawing on the literature on whiteness and everyday nationhood, I put forward a theoretical framework that views immigrant-native relations as unequal configurations unfolding through a symbolic contestation over defining the nation and who belongs to it. In so doing, I aim to bring in the dimension of power when studying immigrant-native relations, a dimension largely overlooked in earlier and contemporary approaches to immigrant integration.

\section{Power, belonging and the study of immigrant-native relations}

In sociology, the relation between immigrants and natives has traditionally been conceptualized as a matter of cultural adaptation. This conceptualization has been informed by normative ideas about whether immigrant populations, described as conglomerates of ethnic groups, should retain their perceived cultural distinctiveness. On one hand, classical assimilation theory has favored and predicted the ceasing of 'ethnic difference', perceived not as a relational phenomenon but as an attribute of immigrant groups. On the other hand, cultural pluralism has challenged assimilationist 
expectations of the dissolution of 'ethnic difference' and has called for equal recognition of the cultural expressions of immigrant groups.

Both theories, as well as the more recent literature on integration, social cohesion and diversity, have been rightfully critiqued for essentializing culture as a property of ethnic groups (Anthias, 2001; Brubaker, 2002; Turner, 1993; Waldinger, 2003a). This problem has been partly overcome by transnationalism and the literature on hybridity and diaspora (Faist, 2000; Hall, 1990). Deploying a constructionist perspective, these theoretical approaches introduce and emphasize individual and collective choice. They emphasize that immigrants develop their sense of identity and community through a syncretism of cultural elements from the countries of origin and settlement and beyond. Claiming that immigrants are able to live to a certain degree in more than one 'social world' at once, scholars of transnationalism and diasporic hybridity have argued for the need to move beyond the nation-state as the basic unit of analysis. In so doing, they have shifted research attention away from the adaptation of sharply differentiated and bounded ethnic groups in the national mainstream; and they have also turned attention to alternative contemporary political projects of belonging and identification. Yet moving beyond the nation-state and conceiving culture in more processual terms is not sufficient to fully grasp the dynamics which characterize immigrant-native relations. As Anthias argues (2001: 619), although approaches to hybridity (and, I would add, transnationalism as well) have admittedly helped 
deconstruct the supposed fixed nature of identity and culture that is so prominent in racialized discourse, they have also in certain cases functioned unintentionally to gloss over existing hierarchies and hegemonic practices. This is especially true in the study of immigrant-native figurations. First, constructions of identity should be always understood as the practical product of the interaction of on-going processes of selfidentification and external categorization (Jenkins, 2008: 76). Immigrants, commonly under the scrutiny of the 'receiving society', are not picking and choosing from among multiple cultures and identities in a voluntaristic manner, free of external forces. An interactional and relational perspective is thus necessary to assess the relative significance of processes of external categorization in their construction of culture and identity. Second, and related to the previous point, immigrant-native relations are not solely mediated by cultural differentiations. They are also embedded in a power configuration whereby immigrants, especially when of low-class standing, are subordinate categories whose 'difference' is questioned and devalued. This configuration unfolds through an unequal power struggle over native society's classifications about who may be a national, and perceptions about how immigrants should behave in order to qualify as members of the nation.

Those classifications and ideologies are not only macro-structural forces produced through the workings of state institutions and formalized by state officials' actions, but equally are enacted and contested through the everyday practices of 
'ordinary people' in different fields of social life. Following Billig's seminal book (1995) on the neglected, less visible, banal expressions of nationalism, an increasing number of scholars are studying nationalism as a major, though largely unconscious, ideological force in the contemporary word. Focusing on the everyday practices of 'ordinary people' in different fields of social life, rather than top-down processes that formed Billig's original focus, they highlight the workings and paradoxes of the everyday reproduction of nationalism. Several of those scholars (Anderson and Taylor 2005; Fox, 2007; Garner, 2012; Jenkins, 2011; Mann, 2011; Skey, 2011; Vassenden, 2010) have paid particular attention to migration and its role in that respect. Immigrants' presence in European states as well as the gradual acknowledgement that 'they are here to stay' has led to increasingly heated discussions on the question as to what it is to be German, Dutch, English, Norwegian, etc. The answers to such questions do not usually challenge received ideas about nationhood; they are rather used to reassemble the national self through discourses that are ultimately entangled with imaginaries of alterity: 'we are what they are not' or 'we are not what they are'. In this fashion the threatened image of the national self (threatened in the sense that becomes the object of discussion) remains mystified and thus secure. At the same time it becomes a weapon of social closure and privilege monopolization (Hage, 2000; Pratsinakis, 2014, 2017; Skey, 2011). 
Scholars contributing to critical race studies have illustrated that 'whiteness' is the superiority ascribed to a 'normalcy' and 'neutrality' unattainable by racialized others. It is an invisible perspective, a dominant and normative space, against which difference is measured (Dyer, 1997; Perry, 2001). As such it constructs a social hierarchy granting differential access to economic and cultural capital and to symbolic resources. It is through a very similar mechanism that native citizens ascribe to themselves a dominant position to their group vis-a-vis migrants. They impose a national order (Hage, 2000; Sayad, 2004) - similar in its function and logic to the racial order (Emirbayer and Desmond, 2015) - in which they claim a dominant position. Their dominant position rests in their ability to present themselves as the standard by which the others have to be judged. Legitimatizing their claims by appeal to the widely held nationalist viewpoint, ${ }^{\mathrm{ii}}$ a viewpoint also shared by different immigrant categories, they gain the authority to intervene successfully in the lives and conditions of existence of those they construct, through their categorizations, as national outsiders.

A perspective that looks at immigrant-native relations as unequal configurations unfolding through a symbolic contestation over defining the nation and who belongs to it, allows us to situate interrelated processes of domination and resistance at the heart of the migration phenomenon. And Elias's work on established and outsider dynamics helps set an alternative analytical approach to study inclusion and exclusion in immigrant-native relations that is more relational and processual than conventional 
approaches in migration studies (Loyal, 2011; Paulle and Kalir, 2014; Pratsinakis, 2013). For instance, the literature on integration and social cohesion in its functionalist framing treats the phenomena of racism, ethnic stigmatization, prejudice and discrimination, as mere intervening factors constraining immigrants' attempts 'to integrate' and state's efforts to facilitate such attempts. To be sure, those phenomena are explored in depth in the context of the thematically broader fields of ethnic and racial studies (and less often through the prism of class analysis). Yet swiftly categorizing processes of social exclusion in immigrant-native figurations as falling into a different field of study altogether is as if we were reducing them to simple epiphenomena of supposed more essential divisions, rather than as processes that should be at the centre of the enquiry of migration phenomenon itself.

As Elias (1998: 106-107) argued, several social problems commonly discussed as racial, ethnic or class phenomena are, in essence, outcomes of the struggle of outsider and established groups that have become interdependent. Studied separately under a variety of different headings, their connections usually remain unexplored while the root common cause of power imbalance is neglected. Thus rather than starting from these categories and trying to provide evidence for the primacy of one over the other, it would be better to ask when, how and through which processes they matter (see Brubaker, 2002; Emirbayer and Desmond, 2015). How do class-based interactions as well as processes of racialization and ethnicization emerge and intersect in immigrant-native 
figurations, under what conditions, and with what effects for different categories? The established-outsiders model allows for answering such questions, helping us to situate the cultural, ethnic, and class dimensions of immigrant-native relations and the intersections of those dimensions within the unequal configuration in which their relation is cast.

\section{The established-outsiders model}

Elias and Scotson's established-outsiders model derives from their study of Winston Parva, a community in England comprising a core neighbourhood and two settlements that had formed around it at later phases. This community manifested a sharp division between the older and the newer group of residents. The older residents closed ranks against the newcomers and stigmatized them as people of lesser worth. Interestingly, the two groups did not differ in terms of nationality, religion, ethnic descent, or class background. The only difference between the two groups related to their length of residency. Their detailed study of the relations between these groups led Elias and Scotson to develop the 'established-outsider figuration': a theoretical model of group relations and stigmatization which, they claimed, could be applied to a wide range of unequal group relations.

The established-outsiders model explains social closure and stigmatization, together with its reverse process, that of collective self-praise, as outcomes of an uneven 
balance of power and the tensions inherent in it. It illustrates how power differences between groups permit the creation of polarized status distinctions between the group charisma claimed by the 'established', and the complementary communal disgrace that they attribute to the 'outsiders'. Speaking about power in the abstract is insufficient.

Elias (1978) rightly argued that power is not a thing which individuals or collectivities possess. Power is, by definition, relational; it needs to be conceptualized as a fluctuating yet structural characteristic embedded in all human relations. The question in established-outsider figurations is how to determine the particular positions of power that the established monopolize, and through which they are able to denigrate the outsiders and secure a positive image of themselves.

Elias and Scotson argued that, in Winston Parva, the conditions of the power imbalance were rooted in the established group's social cohesion, which in turn resulted from its age. The older residents had developed a stock of common memories,

attachments, and dislikes through interaction, and were bound by a cohesive network of kinship ties. Although the newcomers had hardly any intention of attacking the old residents, their arrival was experienced by them as a threat to their established way of life. Their defensiveness in the face of what they perceived as an attack set in motion the mechanism of established and outsider relations.

The ability of the established to control flows of communication permitted them to construct and maintain a positive community identity in opposition to the newcomers. 
Through the workings of 'praise and blame gossip' they built their collective self-image by reference to their 'best' members, and attributed to the outsider group as a whole the 'bad' characteristics of that group's anomic minority (Elias, 1994: xix). Wholesale rejection of the newcomers and taboos against closer contact with them made outsiders emotionally experience their lack of power as a sign of human inferiority. This had a paralyzing effect, undermining their potential to react against and reverse, or at least adjust, the local power ratio.

The figuration derived from Winston Parva may be summarized in the following way: processes of group collective self-praise and stigmatization were initiated by the established in response to subjective feelings of threat from the outsiders; they became possible due to the established group's social cohesion; and they functioned to perpetuate the local dynamics of power. Elias (1994: xvii) treated the Winston Parva case as an 'empirical paradigm' to be tested, enlarged and, if necessary, revised by enquiries into more complex figurations. Yet there are certain underdeveloped points in their 'empirical paradigm' (Pratsinakis, 2013), three of which become all the more obvious when one wishes to apply the model in more complex settings. The first concerns their partial explanation of the reasons why the established perceived the settlement of newcomers as a threat. The second concerns their limited attention to the overarching figuration within which Winston Parva is embedded and their related insufficient theorization on the positions of power that grant the established their 
dominant status. The third concerns their rather too homogeneous presentation of established and outsider groups, which does not allow us to assess their internal dynamics. In the remainder of this paper, I illustrate how those underdeveloped points can be improved while adapting the model to account for immigrant-native figurations resulting from international migration, rather than from internal migration as was the case in the model originally developed.

\section{Established and outsider nationals}

Exploring established-outsider figurations resulting from international migration necessitates turning our attention to the function and significance of ideologies of national belonging. Those ideologies, articulated by means of a widely shared commonsense theory about humanity's division into 'peoples' (Kedourie, 1993), do not only construct identities and communities but situate those within a supposedly naturally existing world of mutually exclusive nations (Billig, 1995). They, and the institutions that support them, turn immigrants into de-facto outsiders as soon as they cross national borders and start building their life abroad, away from their previous 'national home'. In most cases immigrants lack citizenship, which formally attests to their outsider position and deprives them of equal participation in the native society. Besides their exclusion by the state, their outsider status is also experienced in their everyday interactions with members of the native society. Even if citizenship rights are 
acquired, this does not necessarily bring about their acknowledgment as equal members of the national community by the established nationals - i.e. those citizens who consider themselves as representing the national core (Hage, 2000; Pratsinakis, 2014). Prolonged stays by immigrants, especially those of low class standing, are very often seen as a threat to the social cohesion and cultural homogeneity of the nation, initiating processes of outgroup stigmatization and ingroup collective self-praise by the established nationals.

Elias (1994: li) argued that established groups experience the settlement of the newcomers as an attack against their norms and group charisma and against their monopolized power resources. Concerning the former aspect of the perceived attack and with reference to his and Scotson's Winston Parva study, Elias described how the older residents behaved in accordance with a code they had developed over the years. This code was transmitted intergenerationally and was closely associated with self-respect and the respect they felt was due to them from others. Adherence to the norms it prescribed strengthened group feelings and allowed collective pride for the social advancement of any individual member of their community thus underlying their group charismatic beliefs. The different behavioural patterns of the newcomers offended the established group's sensibilities and were taken as a mark of a lower order. Although the newcomers had hardly any intention of attacking the old residents, their arrival was experienced by them as a threat to their way of life. 
Similarly, the literature on everyday nationhood describes how natives vehemently defend everyday practices, banal linguistic forms, and national symbols when those are seen to be offered as a sacrifice to the perceived demands of an increasingly threatening 'other' (Garner, 2012; Jenkins, 2011; Skey, 2011). As Skey explains, such 'shared' symbols, habits and practices construct a moral order and a sense of familiarity and mutual recognition by linking, no matter how tenuously, to other people across the country. They also contribute to the stabilizing of social structures and identities that people rely on to orientate themselves on a daily basis and are crucial elements in securing individuals ontologically, which becomes all the more important in an increasingly uncertain world (Skey, 2011: 94). Unfamiliar behavioural patterns and cultural schemas breach previously taken-for-granted norms about how certain things should be done, and the perceived otherness of newcomers is experienced as a source of threat, a la Garfinkel (Skey, 2011: 158). It also presents an existential challenge opening up to scrutiny hitherto unreflective orthodoxies about the national self. In this context, nationally 'shared' symbols, habits and practices come to form a sort of common cultural currency worth little when used year-in, year-out but whose value grows exponentially when individuals perceive that their symbolic ownership of their nation is being threatened by 'others' whose practicing of their own cultural practices they see as disrespectful behavior and evidence of a lack of willingness 'to integrate' (Pratsinakis, 2014; Skey, 2011: 91-94). 
As Hage (1998: 19) rightly argues, it is only when dominant groups perceive a challenge to their own position as 'occupiers of the centre of national space' and culture that the 'other' becomes a source of anxiety. This brings me to the second, and interrelated, aspect explaining the development of perceptions of threat in established groups, namely their fear of endangerment of their monopolized resources. This is an aspect which, as I have described elsewhere, is undertheorized in Elias' model and empirically unsubstantiated in his research with Scotson (Pratsinakis, 2013: 10-11). Restricting his attention to racial distinctions, Blumer (1958) had developed a theoretical approach to prejudice which provides useful insights in this respect. Blumer explained prejudice as a matter of group relations in a stratified social world. In his view it exists in a sense of group position and exhibits four features on the part of dominant group members: 1) a feeling of superiority; 2) a belief that the subordinate group is intrinsically different and alien; 3) a sense of proprietary claim over certain areas of privilege and advantage; and 4) a perception and suspicion that members of a subordinate group harbour designs on the dominant group's prerogatives. In Blumer's view, prejudice is an emotional recoiling by the established group in the face of threats to their perceived entitlement to either exclusive or prior rights in many important areas of life. Claims of entitlement should not be conceptualized as pertaining only to material resources. They concern tangible things such as access to or control of land, property, jobs and businesses, political decision making, educational institutions, and 
recreational resources, as well as relatively intangible things. The latter may include positions of prestige and the display of the symbols and accoutrements of these positions, as well as access to areas of intimacy and privacy.

Incorporating this element in Elias and Scotson's study, one may re-read the reaction of the established as not only pertaining to concerns over the relative position of the two groups in the abstract (perceptions that the 'morally superior group' should not intermingle with inferiors) but also to the positioning of the two groups in relation to the neighbourhood space, which the established residents felt belonged to them. In a similar fashion, the established nationals assume a managerial role in relation to what they imagine as 'their nation'. They feel they have the right to decide 'how things work here' and 'who should get what'. The arrival of immigrants is perceived as not only ruining their national level intimacy but challenging their exclusive control over 'their' place. Newcomers are seen to be entering what they conceive as their collective private space and they feel they have to discipline them according to the 'rules of the house'. Disciplining or excluding them is necessary in keeping their status as the masters 'in their own nation' and the psychological but also material benefits that flow from it. Belongingness to the nation does not only provide them a certain ontological security but also entails claims for privileged treatment by the state which the established feel is endangered by the presence of newcomers (Garner, 2012; Leitner, 2012). 
But what grants natives the power to put at a disadvantage others who enter their intimate national space? As mentioned earlier, Elias and Scotson argued that, in Winston Parva, the conditions of the power imbalance were rooted in the established group's social cohesion which, in turn, resulted from its age. Are also higher levels of social cohesion the source of power that enables establish nationals to construct a positive image of their collective national self and to question the behavior of others? Making such a claim is obviously problematic. Although it is feasible to speak of and analyse the differing levels of social cohesion of groups at local settings, it is intellectually unsound to transpose such static views of social cohesion at higher levels of analysis. And even if at first sight this may seem to be an inherent limitation of the model, on closer inspection, it appears that it is rather Elias and Scotson's limiting analysis of the Winston Parva study and subsequent theorizing that reduce the scope of the model's theoretical value beyond local settings.

Elias and Scotson's presentation of Winston Parva seems to suggest that the relations between the older residents and the newcomers was bound to the local dynamics and that the structure of the figuration could be sufficiently studied within the confines of the neighbourhood. Their explanation is weakened by their failure to note that the Winston Parva figuration is part of an overarching figuration. The established in Winston Parva cultivated their 'group-charisma' through identification with the more well-off older residents in the neighbourhood, aiming to reduce the distance between 
themselves and middle- and upper-class people living in, or in the immediate surroundings of, Winston Parva. Their self-proclaimed higher levels of social restraint were taken to signify a higher degree of orderliness, circumspection, and foresight all thought to indicate a higher social standing. England was, and still is, a hierarchical society in which classed ideas about respectful and disrespectful behavior shape people's perceptions of each other and about belonging (Mann, 2012). Elias and Scotson rightly pointed to the fact that the ability of the dominant group to maintain an established position in the neighbourhood was not due to (actual) class differences from the outsiders. However, the established were able to legitimize their presumed superiority - in their own eyes and in the eyes of the outsiders - by successfully claiming their belonging to a superior class. Their social cohesion meant that they were able to control flows of communication through which to disseminate their negative categorizations of the outsiders (modeled against positive group self-perceptions) and impose sanctions and taboos against contact with them. But their capacity to construct and maintain a positive image of their group and to collectively denigrate the outsiders rested on their ability to present themselves as the norm by which others in the neighborhood had to abide.

Likewise, natives maintain an established position due to their ability to present themselves as standing for what immigrants have to become in order to gain national recognition. Claiming legitimacy via national ideologies that conceive of a 'national 
people' with common origins and a distinct culture and history, they present their national belongingness as something that is rightfully conferred to them by birth. It is also in relation to this idea of 'the national people' and the concomitant significance attributed to a certain 'race', 'ethnicity', and 'culture' that immigrants are constructed as outsiders, alien, and potentially threatening. Such categorizations do not have a negative impact only on immigrants' feelings of self-worth and psychological well-being. As Eliassi (2010) illustrates in relation to the case of Kurds in Sweden, these categorizations also have significant implications in different social interactions where one's access to societal resources can be limited due to practices of 'ordinary' native citizens who obstruct immigrants' equal participation in society through exclusionary discourses about claim-makings of membership to a national people.

The established nationals reproduce their dominant position not least through the mechanisms detected by Elias in his microsociological research in Winston Parva. One may highlight the reproduction of collective national fantasies that sustain stereotypes about the character of the national self through a multiplicity of national institutions. The significance of the role of the state can be hardly exaggerated in that respect. Sayad (2004: 281) put it eloquently:

It is as though it were in the very nature of the state to discriminate and, in order to do so, to acquire in advance all the necessary criteria of pertinence that are required to make the distinction, without which there can be no national state, between the 'nationals' it recognizes as such and in which it therefore recognizes itself, just as 
they recognize themselves in it [...], and 'others' with whom it deals only in 'material' or instrumental terms.

Except from the state-sponsored narratives and the institutions that circulate those narratives, this process goes hand in hand with the spread of images and flows of information about 'others' in a continuous sort of 'national gossiping' that takes place through popular national media and in everyday public discourse. To be sure, national media do not transmit a single, coherent message and the increasing proliferation of social media further challenges hegemonic representations. Likewise, there are continual controversies and dilemmas to be debated in the public and political discourse which are obviously, by definition, fragmented. Yet despite the different representations held and opinions expressed (some of which are indeed passionately in favor of outsider categories), the very fact that this national gossiping revolves around immigrants' place in the national society, it enacts the established national's self-afforded governmental right to script the nation and renders the outsiders objects of the managerial gaze of an authoritarian, national 'we' (Hage, 2000).

Verily, this 'we' is in itself an object of struggle. At any given time, different factions, whether classes, religions, regions, genders, ethnicities or cultural groups, strive for the power to speak for the nation, and to present their particular voice as the voice of the national whole (Billig, 1995: 71). Obviously, those who construct themselves as established in relation to outsider migrant categories should not be 
thought of as homogeneous categories; different people find themselves in a more or less privileged position in their claims to represent the nation which may also influence the extent to which they feel threatened by newcomers and thus their determination to hit back. Yet acknowledging this hierarchy of the established nationals should not let us overlook the degree to which being recognized as belonging to the nation by virtue of one's descent offers a significant symbolic resource also to weaker categories of natives (Skey, 2011: 46) - a resource which they can utilize in their interpersonal interactions with newcomer groups to put the latter in a disadvantaged position if that is deemed necessary.

Turning to the outsider nationals, they, just like the established, and contrary to Elias and Scotson's presentation, should also be neither considered homogeneous nor static categories. Nations, often built on complex ethnic substrata, draw on competing historical national repertoires underpinning rival symbolic and political projects (Hutchinson, 2005) which can be mobilized selectively either for the inclusion or the exclusion of newcomers. In time, through processes of boundary shifts, groups of people who would earlier be considered as outsiders, enter the erstwhile exclusive national club and are bequeathed the privilege of automatic national membership (Moch, 2003). However, those are long-term processes that span more than one generation. Even though we should not view ideas about nationhood and belongingness as fixed in terms of ethnic, racial and cultural inclusion (Bechhofer et al., 1999), in the 
short run, immigrants usually have limited abilities to alter the ideologies of national belonging to their advantage. As a result, their behavior is judged by the degree of their compliance with the native norms (Antonsich, 2012; Leitner, 2012; Pratsinakis, 2014) and their frame of reference commonly comprises other groups with which they compete for national recognition. Their ability to resist pressure from the dominant society is dependent on their collective and individual resources in symbolic and substantial terms (Pratsinakis, 2014). Paying attention to such processes allows us to enquire into the strategies of different immigrant categories and their motivations ${ }^{\mathrm{iii}}$ which is, in turn, crucial in developing a proper theory of assimilation/segmentation one that does not simply describe outcomes of immigrant-native interaction but explains them as welliv

\section{National outsiders: Resisting pressure, claiming national recognition}

The established nationals view immigrants as candidate members of the nation and they ask them to prove their belongingness by attesting the 'practical nationality' they have accumulated. Practical nationality is the sum of nationally sanctified and valued social and physical cultural styles and dispositions adopted by individuals and groups, as well as valued characteristics within a national field: looks, accent, demeanors, taste, nationally valued social and cultural preferences and behavior, length of residency, etc. (Hage, 2000: 53). According to Hage (2000), the recognition and legitimacy given to a 
person or a group for their stock of practical nationality is translated into different degrees of national acceptance.

Thinking along these lines, we may reassess acculturation as solely the process of acquisition of social skills that are functional within a cultural system. Acculturation is also a process whereby immigrants, as outsiders, adopt the standards of judgement of the established - that is, the very standards according to which their culture is commonly devaluated (Waldinger, 2003a). The immigrants' display of growing attachment to the native society is an attempt to achieve approval as respectable members of the national community. It is also a practice of de-stigmatization, an attempt to distance themselves from the stigma of the national outsider and, as such, it is more pressing for groups and individuals at the bottom of the national hierarchy (Pratsinakis, 2014).

According to Hage (2000), the extent to which immigrants are successful in the process of practical nationality accumulation depends on their habitus, the cultural dispositions and embodied social knowledge that they bring with them. Yet one must remark that it is also heavily determined by the positioning of their ethnic, 'racial' and religious background in relation to a historically constructed self-image of 'the nation' to which they aspire to belong. These positionings construct an ethnic hierarchy that determines the varying degrees of pressure that different immigrant categories experience to comply with the native norms (see Koskela, 2014). Moreover, not all 
practical nationality is acquirable. For instance, a Muslim, non-European immigrant with a long residency in a West European country, who has accumulated practical nationality in the form of the dominant linguistic and cultural dispositions may yield less national belonging in relation to a newcomer Christian immigrant of a neighbouring European state, even if the latter is less acquainted with the native language. There are limits in the accumulative character of practical nationality notably related to an outsider's religion (Ryan, 2011) and their ethnic and racial categorization by the dominant society (see Leddy-Owen, 2014).

In relation to race in particular, in the US, access to whiteness as a resource has been sought by successive waves of immigrants with different national groups competing with each other in an effort to be whiter and gain privileged access to material symbolic and social capital (Garner, 2006). Similarly, Fox (2013) in a contemporary setting shows how whiteness afforded Hungarian and Romanian immigrants an important advantage in inserting themselves into Britain's racialized hierarchies, an advantage that they were not hesitant to exploit. And even if whiteness should not be seen as an objective status but rather as a claim subjected to continuous contestation, phenotypically differences do limit the discursive and performative abilities of certain categories and render others a better position.

Finally, immigrant-native relations are not only mediated by ethnicity, race and religion but by class as well. The demand by natives that immigrants comply with the 
native rules of conduct and demonstrate their practical nationality is expressed in a much more pressing way for lower-class immigrants. It is those immigrants who appear more threatening to natives - a view that is intensified by current public policies in many destination countries distinguishing between the welcome highly skilled professionals and the unwelcome labour immigrants (Faist, 2013). Moreover, for more affluent and highly educated immigrants, their higher-class background acts as a shield and protects them to a certain extent against native judgement. Even if questioned regarding their belongingness, they are more powerful in countering the accusations expressed by native citizens. This protection, however, is not absolute as the autoethnographic study of Davis and Nencel (2011) in the Netherlands shows. In addition, it should be assessed in relation to how their religious, ethnic and 'racial' background is valued by native society in the first place; not all highly skilled immigrants are similarly evaluated within a country. For instance, Koskela (2014) shows how a distinction between 'wanted' highly skilled and 'unwanted' humanitarian migrants in Finland has granted the former a significantly higher position in the local migrant hierarchy. However, this position is not equally high for every highly skilled migrant. Non-western highly skilled migrants are less accepted and their categorization as culturally different burdens their interaction with the dominant society on many occasions. 
National narratives and histories commonly contain information about particular 'others' as well as stereotypical views about different countries from which immigrants come. National media also circulate information about immigrants who are evaluated according to those national narratives and the perceived interests of the state. These flows of information impact on people's perceptions of immigrant groups. Flows of information and experiences of actual interaction shape the public images of immigrant and ethnic categories. The severity with which native judgment is addressed towards an immigrant category is a direct function of the public image of that immigrant category at a given time. The stock of practical nationality of immigrants, together with their legal status, ethnic and 'racial' backgrounds, and their socio-economic status, determines their vulnerability to such judgment and their symbolic capacity to challenge it. Commonly those dimensions are homologous: the more vulnerable the members of a migrant category are, the less is their symbolic capacity to challenge the public image that shapes their vulnerability.

Yet in contrast to the terms dominant-dominated and superordinarysubordinary, which imply a static condition of domination, the very formulation of 'established and outsiders' indicates a tension - a contestation over certain positions of power. Thus, in the short run, our attention should be put on the ways and degrees to which immigrants assert their agency to resist and contradict discriminatory patterns that devalue their background and ultimately exclude them from social resources in the 
receiving society. An intersectional perspective may provide valuable insights in that respect. First, it helps us keep a basic axiom in sociology that social relations have a potentially infinite number of dimensions deriving from social constructions of differences in physical and cultural characteristics. Anything that influences expected behavior can be treated as a dimension, though there is no separate dimension of power; differences of power can be significant in any dimension (Banton, 2008). Second, as Anthias (2013: 335) argues, the complexity of social identities means not only that there are a great number of relationships mutually influencing each other but also that social divisions are irreducible and dialogical. By irreducible she means that social divisions cannot be explained through a process of reduction to other categories and, by dialogical, she means that they operate not as stand-alone categories in the realm of social practice but rather in the context of each other, at times producing fissures as well as amplifications of inequality.

In my ethnographic research in a neighborhood of the City of Thessaloniki, Greece (Pratsinakis, 2013), I have highlighted the intersecting roles of ethnicity and class in shaping native people's evaluation of different immigrant categories as well as determining the strategies of immigrants in challenging and questioning those evaluations. This research focused on immigrants from the former Soviet Union, both of Greek descent (FSU Greeks) - who formed the majority in the neighborhood - and of non-Greek descent, as well as Albanian immigrants. According to the findings, more 
well-to-do Russian immigrants appeared to be better received by native Greeks in their everyday interactions, as compared those FSU Greeks of lower class standing who found it difficult to prove their Greekness and who were, in many cases, re-categorized by native Greeks as false Greeks (Pratsinakis, 2017). The higher socio-economic status of the former seemed to protect them from native judgement. FSU Greeks of higher socio-economic status, however, were in a more powerful position. Being of actual Greek descent and able to prove it, they not only enjoyed the recognition of native Greeks but could make them adopt an apologetic and defensive stance for not being respectful towards other Greeks.

At the other end of the spectrum, Albanian immigrants, a stigmatized immigrant group in Greece at the time the research was conducted, had to actively attest their practical nationality in an attempt to show - against native perceptions - that they do not differ from native Greeks. They negotiated their identity as individuals, in some cases contrasting themselves to 'the bad Albanians' and without always challenging negative dominant perceptions about their ethnicity. The devaluation of their national background and the stigmatization of their collective identity were experienced as a burden in their everyday life. Equally constraining were negative images for lower-class standing, Turkic-speaking, FSU Greeks, whose Greekness was denied by natives and who were re-categorized by them as false Greeks. Their difference from Albanian immigrants, however, was that Turkic-speaking FSU Greeks came to Greece as Greeks 
with high expectations of a life in the homeland. They were not willing to adopt social behaviors that would be better accepted by native Greeks; they thought of such an attitude as submissive. Their reaction to denigrating attitudes held by native Greeks was to engage in confrontation with them. This latter finding, which is in line with Waldinger's (2003a) analysis about the 'second generation revolt' in the US', suggests that excluded groups that feel part of the nation may be the most eager to engage in confrontation with the native society to claim recognition.

Specifying how ideologies of national belonging work in everyday immigrantnative interaction, as was done in the previously cited study, are crucial in uncovering the hegemonic relations of inequality which they sustain. Further research is necessary to access how those hegemonic relations unfold in different (national) contexts and what type of rhetorical repertoires and repertoires of action they allow to different immigrant categories in their attempt to claim a better position in the ethnic hierarchy in a given nation. Such research needs also to recognize the multiple levels at which the established-outsider figurations operate. For instance, previous research has shown that, at the local level, certain migrant categories are able to reverse, or at least adjust, the power ratio between them and established nationals when their communities are characterized by a strong internal cohesion (May, 2004; Pratsinakis, 2014). Yet that does not allow them to generally claim an established position, forcefully reminded of their outsider status in several encounters with native nationals outside their 
neighborhood (May, 2004; Pratsinakis, 2014). Finally, research at the level of individual interaction that does not necessarily generalize at the level of groupings may be more suitable to account for the permeable internal boundaries of the established nationals who, as noted, just like immigrants are divided along ethnicity, class and gender lines. It could also account for other axes of identity and stratification, not touched upon here, such as age and sexuality, and the ways they influence immigrant-native interactions and positionings.

\section{Conclusion}

The question as to 'who belongs' is often contested and hence politicized; the nationstate is simply one among the many loci of contestation over membership. Yet contrary to certain post-nationalist arguments, it remains a particularly consequential one

(Brubaker, 2010: 64). Its importance is not only attested in the historical development of increasingly direct, intrusive, and centralized forms of state rule that lay emphasis upon belonging and formalized membership (Brubaker, 2010; Sayad, 2004), but also in the widespread acceptance of the nationalist viewpoint which is to a large extent ingrained in the contemporary consciousness (Billig 1995). Understandings of who forms part of the nation, who may become a member and under what conditions, and who is to be excluded, as well as the contestation of those understandings, are central in grasping the 
power dynamics underlying immigrant-native relations. They often also shape the relations between different immigrant categories which are in many cases competing for national belonging (Hage, 2000; Pratsinakis, 2013; Waldinger, 2007).

The power dimension of immigrant-native figurations relating to ideologies of national belonging has been rather neglected by migration scholars. That is particularly the case with the literature on integration, which has been largely preoccupied with uncritical description of how the process of nation-building evolves in the face of 'the migration challenge' (Favell, 2003; Waldinger, 2003b), thus assuming the very ideas it should be questioning and analysing. It has also largely been missed by more recent approaches which, in their attempt to overcome the 'container model' of society that methodological nationalism has imposed on the sociology of migration, and in their attempt to go beyond earlier essentialized conceptions of (ethnic) identity, have in many cases lost sight of the significance of nationalist thought-frames in shaping people's self-conceptions, position in society, and relations with others.

In this paper it is suggested that, rather than assuming the nationalistic viewpoint or ignoring it as if it did not matter, we should uncover, analyse, and problematize the hegemonic power of ideologies of national belonging in structuring immigrant-native relations. By conceptualizing immigrant-native relations and the process of integration in terms of an established-outsider figuration, attention is redirected from the immigrants alone to the process of mutual entanglement that takes place between 
immigrants and natives in different fields of life. It thus forces us to conceive of the established nationals as a constitutive part of the figuration, and as a result we can sidestep the trap of assuming their standpoint. It further helps highlight the power dimension of this process: how immigrant-native relations unfold through an unequal power struggle emerging through a symbolic contestation over defining the nation and who belongs to it. This analytical approach provides us with a relational and processual theoretical framework which allows us to situate the cultural, ethnic, racial and class dimensions of immigrant-native relations within the unequal configuration in which their relation is cast.

\section{Acknowledgements}

I would like to thank the two anonymous reviewers for their very helpful and constructive comments and Yannis Tzaninis for his support in the writing process.

\section{References}

Alba RD and Nee V (2003) Remaking the American Mainstream: Assimilation and Contemporary Immigration. Cambridge: Harvard University Press.

Anderson K and Taylor A (2005) Exclusionary Politics and the Question of National Belonging Australian Ethnicities in 'Multiscalar' Focus. Ethnicities 5(4): 460-485.

Anthias F (2001) New hybridities, old concepts: the limits of 'culture'. Ethnic and Racial Studies 24(4): 619-641. 
Anthias F (2013) Hierarchies of social location, class and intersectionality: Towards a translocational frame. International Sociology 28(1): 121-138.

Antonsich M (2012) Exploring the demands of assimilation among white ethnic majorities in Western Europe. Journal of Ethnic and Migration Studies 38(1): 59-76.

Banton M (2008) Methodological Nationalism? Paper presented at the annual IMISCOE Conference 2008, Bilbao, September 11.

Bechhofer F, McCrone D, Kiely R and Stewart R (1999) Constructing national identity: arts and landed elites in Scotland. Sociology 33(3): 515-534.

Billig M (1995) Banal Nationalism. London: SAGE publications Ltd.

Blumer H (1958) Race prejudice as a sense of group position. Pacific Sociological Review 1(1): 3-7.

Brubaker R (2002) Ethnicity without groups. European Journal of Sociology / Archives Européennes De Sociologie 43(02): 163-189.

Brubaker R (2010) Migration, membership, and the modern nation-state: Internal and external dimensions of the politics of belonging. Journal of Interdisciplinary History 41(1): 61-78.

Brubaker R, Feischmidt M, Fox J and Grancea L (2006) Nationalist Politics and Everyday Ethnicity in a Transylvanian Town. Princeton NJ: Princeton University Press.

Coutin SB (2010) Confined within: National territories as zones of confinement. Political Geography 29(4): 200-208.

Davis K and Nencel L (2011) Border skirmishes and the question of belonging: An authoethnographic account of everyday exclusion in multicultural society. Ethnicities 11(4): 467-488.

Dyer, R (1997) White. London: Routledge.

Edensor T (2002) National identity, popular culture and everyday life. Oxford: Berg.

Elias N (1978) What is Sociology? New York: Columbia University Press.

Elias N. (1998) Group charisma and group disgrace. In: Mennell S \& Goudsblom J (eds) Norbert Elias on Civilization, Power, and Knowledge: Selected Writings. Chicago, University of Chicago Press, 104-112. 
Elias N (1994) A theoretical essay on established and outsider relations. In: Elias N and Scotson JL The Established and the Outsiders: A Sociological Enquiry into Community Problems, 2nd edn., pp. xv-lii. London: Sage

Elias N and Scotson JL (1994) The Established and the Outsiders. 2nd ed. London: Sage Publications Limited.

Eliassi B (2010) A Stranger in My Homeland: The Politics of Belonging among Young People with Kurdish Backgrounds in Sweden. Unpublished doctoral thesis, Mid Sweden University.

Emirbayer M and Desmond M (2015) The Racial Order. Chicago, IL: University of Chicago Press.

Faist T (2000) The Volume and Dynamics of International Migration and Transnational Social Spaces. Oxford: Oxford University Press.

Faist T (2013) The mobility turn: a new paradigm for the social sciences? Ethnic and Racial Studies 36(11): 1637-1646.

Fassin D (2011) Policing Borders, Producing Boundaries. The Governmentality of Immigration in Dark Times*. Annual Review of Anthropology 40: 213-226.

Favell A (2003) Integration nations: the nation-state and research on immigrants in Western Europe. Comparative Social Research 22: 13-42.

Fox JE (2007) From national inclusion to economic exclusion: ethnic Hungarian labour migration to Hungary. Nations and Nationalism 13(1): 77-96.

Fox, JE 2013, "The uses of racism: whitewashing new Europeans in the UK", Ethnic and Racial Studies, vol. 36, no. 11, pp. 1871-1889.

Garner S (2006) The uses of whiteness: what sociologists working on Europe can draw from US research on whiteness. Sociology 40(2): 257-275.

Garner S (2012) A moral economy of whiteness: Behaviours, belonging and Britishness. Ethnicities 12(4): 445-464.

Hage G (2000) White Nation: Fantasies of White Supremacy in a Multicultural Society New York: Routledge. 
Hall S (1990) Cultural identity and diaspora. In Rutherford J (ed), Identity: Community, Culture, Difference. London: Lawrence and Wishart

Hutchinson J (2005) Nations as zones of conflict London: Sage.

Jenkins R (2008) Rethinking Ethnicity London: Sage.

Jenkins R (2011) Being Danish: Paradoxes of Identity in Everyday Life. Copenhagen: Museum Tusculanum Press.

Kedourie E (1993) Nationalism. Oxford: Blackwell.

Kofman E (2005) Citizenship, migration and the reassertion of national identity. Citizenship Studies 9(5): 453-467.

Koskela K (2014) Boundaries of Belonging: Highly Skilled Migrants and the Migrant Hierarchy in Finland. Special issue of Journal of Finnish Studies 17 (1/2): 19-41.

Leddy-Owen C (2014) Reimagining Englishness: 'Race', class, progressive English identities and disrupted English communities. Sociology: 0038038513516829.

Leitner, H (2012) Spaces of encounters: Immigration, race, class, and the politics of belonging in small-town America, Annals of the Association of American Geographers, 102 (4): 828-846.

Loyal S (2011) A land of a hundred thousand welcomes? Understanding established and outsiders relations in Ireland. The Sociological Review 59: 181-201.

Malkki LH (1995) Refugees and exile: From" refugee studies" to the national order of things. Annual Review of Anthropology 24: 495-523.

Mann R (2011) 'It just feels English rather than multicultural': local interpretations of Englishness and non-Englishness. The Sociological Review 59(1): 109-128.

Mann R (2012) Uneasy being English: The significance of class for English national sentiments. Ethnicities 12(4): 484-499.

May DM (2004) The interplay of three established-outsider figurations in a deprived inner-city neighbourhood. Urban Studies 41(11): 2159-2179.

Moch LP (2003) Moving Europeans: Migration in Western Europe since 1650. : Indiana University Press. 
Paulle B and Kalir B (2014) The integration matrix reloaded: from ethnic fixations to established versus outsiders dynamics in the Netherlands. Journal of Ethnic and Migration Studies 40(9): 1354-1374.

Perry P (2001) White Means Never Having to Say You're Ethnic White Youth and the Construction of "Cultureless" Identities. Journal of Contemporary Ethnography 30(1): 56-91.

Pratsinakis M (2014) "Resistance and Compliance in Immigrant-Native Figurations: Albanian and Soviet Greek Immigrants and their Interaction with Greek Society." Journal of Ethnic and Migration Studies 40 (8): 1295-1313.

Pratsinakis M (2013) "Contesting National Beloging: An Established-Outsider Figuration on the Margins of Thessaloniki, Greece." Doctoral thesis, Ipskamp Drukkers: Amsterdam

Pratsinakis M (2017) "Collective charisma, selective exclusion and national belonging: 'false' and 'real' Greeks from the former Soviet Union" in Everyday Nationhood: Theorizing, Culture, Identity and Belonging two decades after the publication of Banal Nationalism, eds M. Skey \& M. Antonsich. Houndmills: Palgrave

Pratsinakis M, Hatziprokopiou P, Labrianidis L and Vogiatzis N (2015) Living together in multi-ethnic cities: People of migrant background, their interethnic friendships and the neighbourhood. Urban Studies: 0042098015615756.

Ryan, L (2011) Muslim Women Negotiating Collective Stigmatisation: 'We're Just Normal People' Sociology, 45(6): 1045-1060

Sayad A (2004) The Suffering of the Immigrant. Cambridge: Polity.

Skey M (2011) National Belonging and Everyday Life: The Significance of Nationhood in an Uncertain World. Houndmills, Basingstoke: Palgrave Macmillan.

Turner BS (2007) The enclave society: towards a sociology of immobility. European Journal of Social Theory 10(2): 287-304.

Turner T (1993) Anthropology and Multiculturalism: What is Anthropology that Multiculturalists should be Mindful of it? Cultural Anthropology 8(4): 411-429.

Van Houdt F, Suvarierol S and Schinkel W (2011) Neoliberal communitarian citizenship: Current trends towards 'earned citizenship' in the United Kingdom, France and the Netherlands. International Sociology 26(3): 408-432. 
Vassenden A (2010) Untangling the different components of Norwegianness. Nations and Nationalism 16(4): 734-752.

Waldinger R (2003a) The Sociology of Immigration: Second Thoughts and Reconsiderations. In: Reitz GJ (ed) Host Societies and the Reception of Immigrants. San Diego, CA: Center for Comparative Immigration Research, 21-43.

Waldinger R (2003b) Foreigners transformed: International migration and the remaking of a divided people. Diaspora: A Journal of Transnational Studies 12(2): 247-272.

Waldinger R (2007) The bounded community: turning foreigners into Americans in twenty-first century LA. Ethnic and Racial Studies 30(3): 341-374.

Wimmer A and Glick Schiller N (2002) Methodological nationalism and beyond: nation-state building, migration and the social sciences. Global Networks 2(4): 301334.

Yuval-Davis N (2011) The Politics of Belonging: Intersectional Contestations. London: Sage.

${ }^{\mathrm{i}}$ The theoretical elaboration of the model is outlined primarily in an introduction that Elias dictated ten years after the publication of the book for its Dutch translation, published in English in the second edition of the book. In this paper citation is made to Elias when I refer to the theoretical introduction and to Elias and Scotson when I refer to the original book.

ii The nationalist viewpoint is not defined here as the radical expression of national consciousness exalting one nation above all others; it refers rather to a standpoint, widely held in the modern world, that takes for granted ideas about nationhood and the link between peoples and homelands, and about the naturalness of the world of nations, divided into separate homelands (Billig, 1995: 61).

iii Thus correcting for a rather underdeveloped point in Elias' theorizing.

iv Even Alba and Nee's Remaking the American Mainstream (2003), possibly the most thorough attempt to develop such a theory, reads as a valuable historiography of assimilation rather than a proper theory. Their concept of 'distal causes' is too broad to have explanatory 
value leading to a confusion between processes and their causes in a circuitous reasoning that leaves the reader thinking that assimilation happens simply because it happens.

v In Waldinger's (2003a) view, second-generation revolt is only partly material, relating to migrants' children's lack of willingness to consent to circumstances that their forefathers may have accepted due to their exposure in different wage and consumption standards. The major reason lays in that they understand themselves as insiders, as fully fledged Americans, and thus maintaining their sense of self-worth presumes access to what the American Democracy is supposed to promise to its nationals. In short, according to Waldinger, fully Americanized immigrants and their descendants are unlikely to accept the subordination that the new arrivals may take as a given. 